Case Report

Open Access

\title{
Retrorectal Cystic Hamartoma: An unfrequent benign but Potentially Malignant Tumour in Adults
}

Bascuas-Rodrigo B, Juan Carlos Gomez Rosado*, Valdés-Hernández J, Del-Río-Lafuente F, Cintas-Catena J, Torres-Arcos C, Perez-Sanchez A, Oliva-Mompeán F and Capitán-Morales LC

Hospital Universitario Virgen Macarena de Sevilla, Unidad de Coloproctología, Facultad de Medicina, Universidad de Sevilla, Spain

\section{Article Info}

*Corresponding author:
Juan Carlos Gomez Rosado
Hospital Universitario Virgen Macarena de
Sevilla
Unidad de Coloproctología
Facultad de Medicina
Universidad de Sevilla
Spain
E-mail: dr.gomez.rosado@gmail.com

Received: June 22, 2018

Accepted: July 17, 2018

Published: July 21, 2018

Citation: Bascuas-Rodrigo B, Gómez-Rosado JC, Valdés-Hernández J, et al. Retrorectal Cystic Hamartoma: An unfrequent benign but Potentially Malignant Tumour in Adults. Madridge J Surg. 2018; 1(2): 44-46.

doi: $10.18689 /$ mjs-1000111

Copyright: (c) 2018 The Author(s). This work is licensed under a Creative Commons Attribution 4.0 International License, which permits unrestricted use, distribution, and reproduction in any medium, provided the original work is properly cited.

Published by Madridge Publishers

\begin{abstract}
Tailgut cysts are rare congenital developmental lesions located in the retrorectal space that usually appear as asymptomatic lesions in middle-aged women, so they are often misdiagnosed or found incidentally during evaluation for other conditions. Complete surgical excision is the best therapeutic option for these tumours.

We describe the case of a 57-year-old female referred to our service due to persistence of intergluteal cleft mass after excision of pilonidal sinus with as only symptoms. CT of the pelvis with contrast, abdominal US and pelvic MRI revealed a welldefined and homogeneous cystic mass in the presacral area that surrounds the coccyx extending to retrococcygeal space compatible with tailgut cyst, that required complete surgical. Final pathological diagnosis was retrorectal cystic hamartoma with no evidence of malignancy. The patient was discharged 48 hours after surgery and nowadays, she remains symptom free with no evidence of recurrence.
\end{abstract}

Keywords: Retrorectal mass; Retrorectal space; Tailgut cyst; Retrorectal cystic hamartoma; Surgical management.

\section{Purpose}

Presentation of a rare case of retrorectal cystic hamartoma located in the retrorectal region.

\section{Case Report}

We present a case of a 57-year-old female with a medical history of hypertension, hepatitis $C$ with associated arthritis, degenerative disc disease, fibromyalgia, cholecystectomy, mammoplasty and excision of pilonidal sinus.

The patient was referred to our service due to persistence of intergluteal cleft mass after excision of pilonidal sinus. Her symptoms have been present during the last months and included swelling and local tenderness. No other symptoms were present.

Physical exam showed a subcutaneous mass at the coccygeal area with elastic consistency and completely independent from the rectum. Laboratory studies were unremarkable.

Contrast enhanced CT of the pelvis, abdominal US and pelvic MRI revealed a $9.6 \times 5.8 \times 2.4 \mathrm{~cm}$ well-defined and homogeneous cystic mass in the presacral area surrounding the coccyx, and extending to retrococcygeal space. 


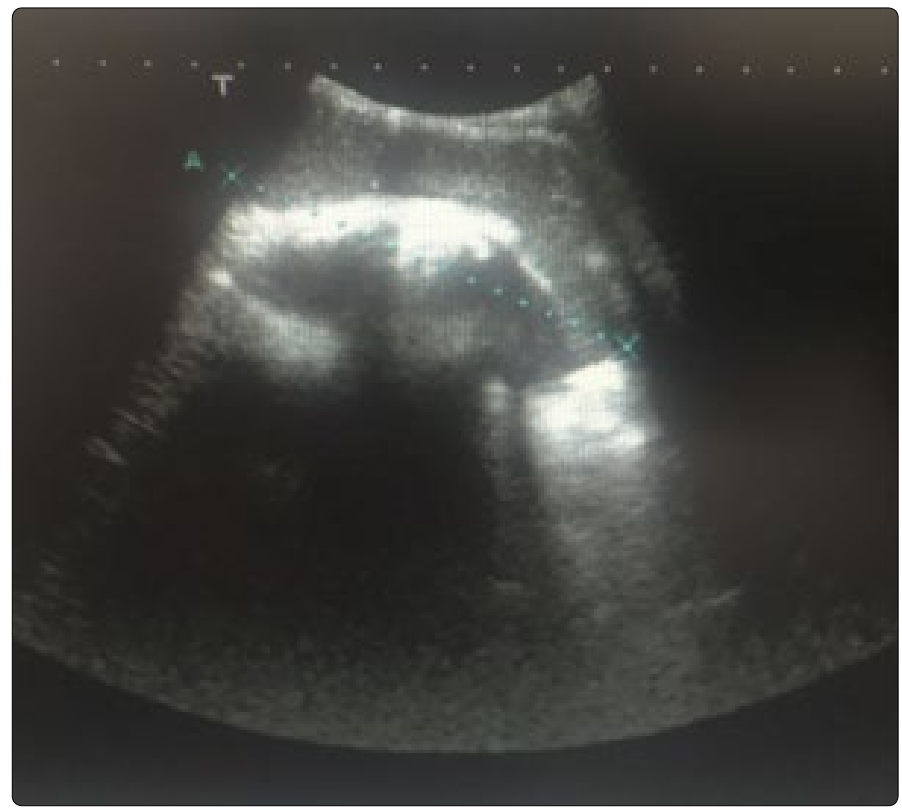

Figure 1. US image

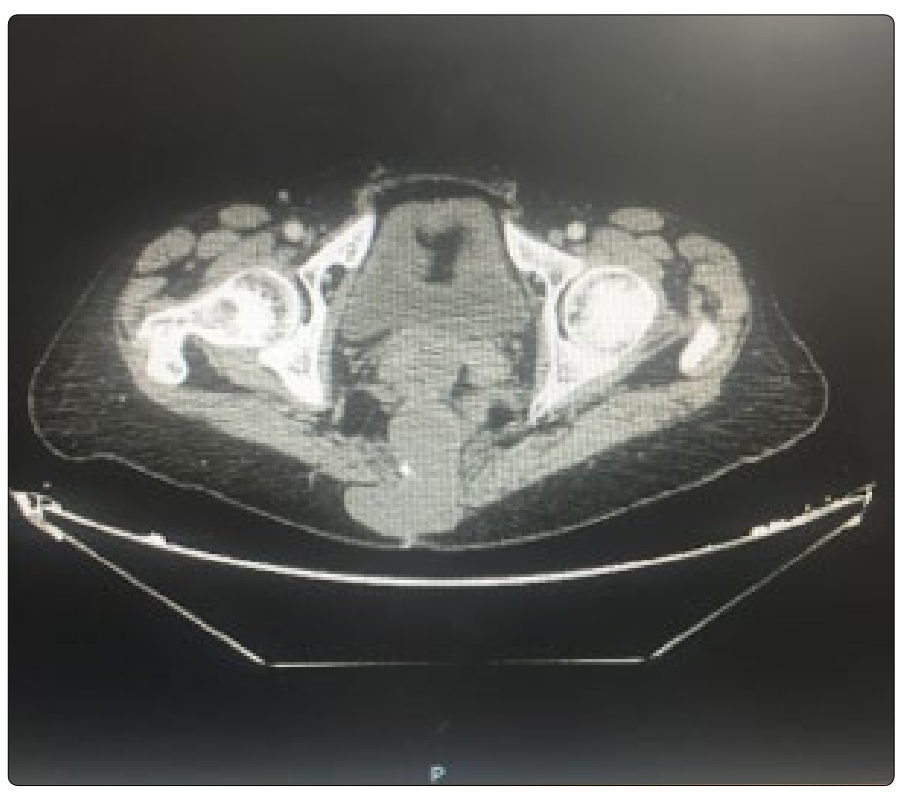

Figure 2. СT Axial

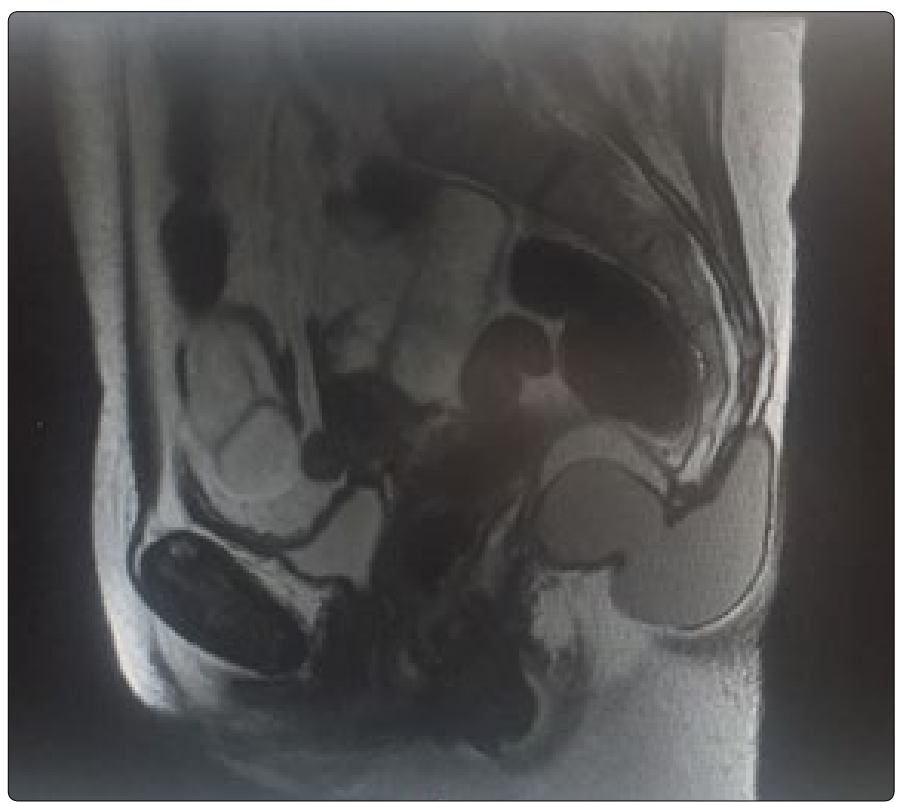

Figure 3. MRIsagital
These findings were compatible with tailgut cyst as the first option, so we decided undergo surgery, performing a complete excision of the tumour with a posterior approach.
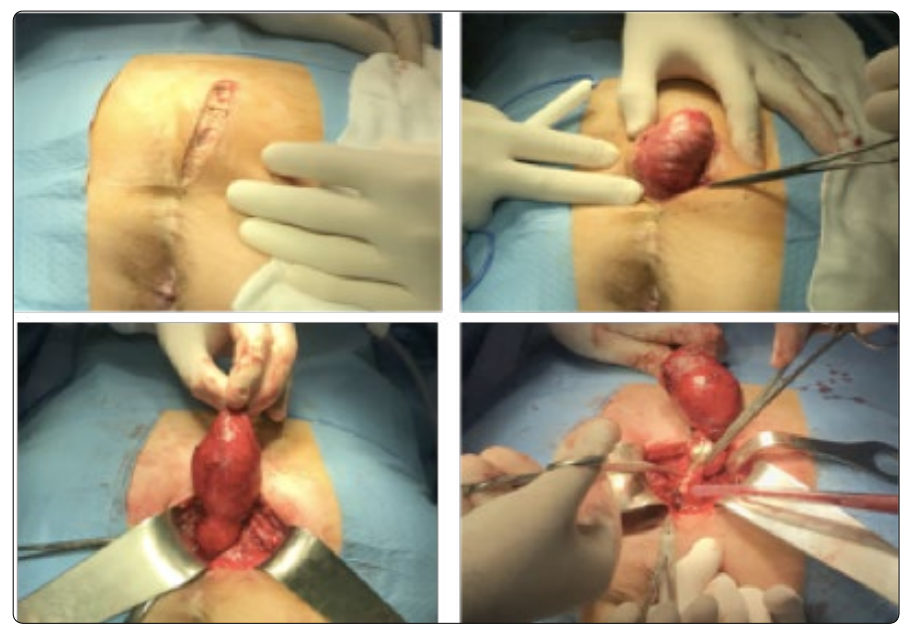

Figure 4. Surgical management

The final pathological diagnosis was retrorectal cystic hamartoma (tailgut cyst) with no evidence of malignancy. Post-operative course was uneventful and the patient was discharged 48 hours after surgery.

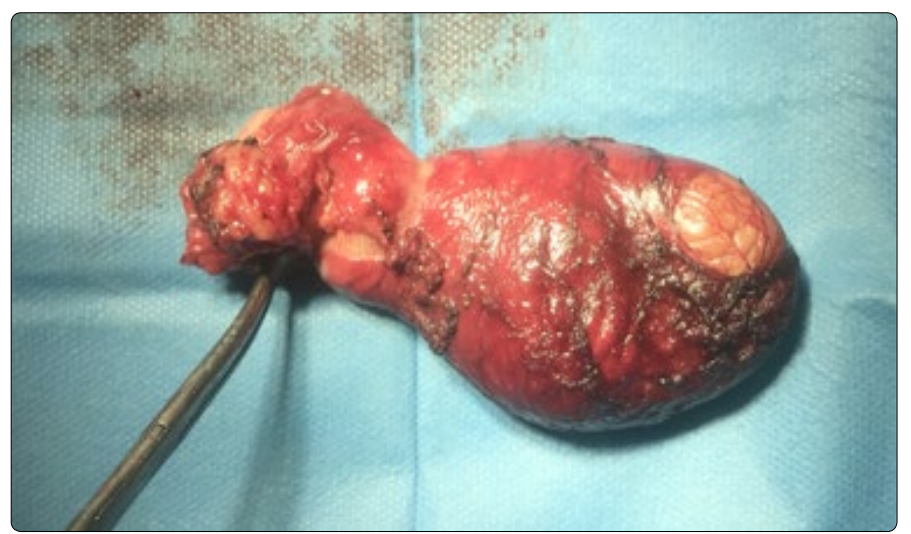

Figure 5. Specimen

Nowadays, our patient remains symptom-free with no evidence of recurrent or residual disease.

\section{Discussion}

Retrorectal (or presacral) space is an anatomic area between the posterior wall of the rectum and the anterior surface of the sacrum, extending upwards to the peritoneal reflection and downwards to the rectosacral fascia (Waldeyer). The lateral boundaries are the endopelvic fascia (lateral ligaments), ureters and iliac vessels [1].

Due to the presence of multiple embryologic remnants and miscellany of tissue types within this area, this space can develop a wide variety of benign and malignant conditions, which most commonly present in the form of masses [2].

The tailgut cyst, also known as retrorectal cystic hamartoma, is one of the rare congenital malformations which may present in the presacral space. It is an uncommon congenital developmental lesion arising from post-natal primitive gut remnants $[3,4]$. 
They can present at any age, although they usually appear between the ages of 30 and 60 with a strong predominance in females $(3: 1)[5,6]$.

The anatomical position and rarity of the lesion leads to difficulty firstly in diagnosis (the lesion is often misdiagnosed) and secondly in surgical management (the condition is often sub-optimally managed) [7]. That is why pre-operative highresolution modern imaging techniques (pelvic computed tomography (CT) or magnetic resonance imaging (MRI)) play such a crucial role in differential diagnostics and planning the surgical management of retrorectal lesions. Tomographic imaging, with either computed tomography or MRI, has become the standard for preoperative evaluation of retrorectal tumours. In particular, MRI with an endorectal coil can provide detailed images depicting the relationship of the tumour with sacral nerve roots, coccyx, as well as musculature of the pelvic floor, and also appears to be slightly more specific for establishing the histology of the retrorectal tumor [8].

A diagnostic biopsy is not recommended due to the risk of spillage of malignant cells or spread of infection into the abdominal cavity [9]. Only in cases of unresectable lesions, or in patients with significant comorbidity that precludes pelvic surgery, may biopsies be performed for histological diagnosis if required to indicate adjuvant or palliative therapy [10].

Nowadays, complete surgical resection remains the cornerstone of treatment, and it should be undertaken by surgeons with expertise in complex pelvic operations. Surgical resection is the best therapeutic option once the diagnosis is established, even in asymptomatic patients as there is potential for growth or malignancy [10]. However, surgical management may be challenging, not only technically but also in determining the most appropriate approach. Three different operative approaches are commonly used in the resection of retrorectal tumours: abdominal, transsacral, and combined abdominosacral. Approach depends on the nature and location of the lesion [11]. Lesions that do not extend below S4 can be resected transabdominally (anterior approach); lower lesions can be resected transsacrally (posterior approach); and larger lesions or those in an intermediate position may require a combined abdominal and sacral operation. The selection of approach is the key to successful treatment and is determined by the nature (morphology), localization, size of the retrorectal lesion and its relationship with adjacent structures.

Therefore, to decide the best surgical approach, an individual and multidisciplinary analysis must be carried out.

\section{Conclusion}

Primary tumours of the retrorectal space are very rare. Due to their anatomical position and variable presentation these lesions are often misdiagnosed or found incidentally during evaluation for other conditions. Complications include infection and malignant transformation that is the reason why surgical treatment is always indicated. Complete surgical resection with negative margins still remains the cornerstone of surgical treatment, as this eliminates the potential of recurrence, haemorrhage, infection, compression and malignant changes. Surgical management should be tailored individually for each patient, based on the advantages and disadvantages of each surgical approach. Successful treatment of these lesions requires extensive knowledge of pelvic anatomy and expertise in pelvic surgery.

\section{References}

1. Aranda-Narvaez JM, Gonzalez-Sanchez AJ, Montiel-Casado C, SanchezPerez B, Jimenez-Mazure C, et al. Posterior approach (Kraske procedure) for surgical treatment of presacral tumors. World J Gastrointest Surg. 2012; 4(5): 126-130. doi: 10.4240/wjgs.v4.i5.126

2. Haydar M, Griepentrog K. Tailgut Cyst: A case report and literatura review. Int J Surg Case Rep. 2015; 10: 166-168. doi: 10.1016/j.jijscr.2015.03.031

3. Smit R, Gregorini D, Beltran R, Martorelli J, Granada G, Lespi P. Retrorectal cyst hamartoma: report of a pediatric case. Arch Argent Pediatr. 2010; 108(3): e82-85. doi: 10.1590/S0325-00752010000300015

4. Lim SW, Huh JW, Kim YJ, Kim HR. Laparoscopy-assisted resection of tailgut cysts: report of a case. Case Rep Gastroenterol. 2011; 5(1): 22-27. doi: $10.1159 / 000322912$

5. Ghosh J, Eglinton T, Frizelle FA, Watson AJ. Presacral tumours in adults. Surgeon. 2007; 5(1): 31-38

6. Uhlig $B E$, Johnson RL. Presacral tumors and cysts in adults. Dis Colon Rectum. 1975; 18(7): 581-596. doi: 10.1007/BF02587141

7. Kildusis1 E, Evaldas Samalavicius N. Surgical management of a retro-rectal cystic hamartoma (tailgut cyst) using a trans-rectal approach: a case report and review of the literatura. J Med Case Rep. 2014; 8:11. doi: 10.1186/1752-1947-8-11

8. Singer MA, Cintron JR, Martz JE, Schoetz DJ, Abcarian H. Retrorectal cyst: a rare tumor frequently misdiagnosed. J Am Coll Surg. 2003; 196(6): 880886. doi: 10.1016/S1072-7515(03)00133-9

9. Ostiz M, Yanguas N, Jimenez G, Gonzalez G, Fernandez de los Reyes I. Retrorectal cystic hamartoma (tailgut cyst): an uncommon cause of recurrent abdominal pain. An Sist Sanit Navar. 2017; 40 (2): 303-307. doi: 10.23938/ASSN.0038

10. Schwarz RE, Lyda M, Lew M, Paz IB. A carcinoembryonic antigen-secreting adenocarcinoma arising within a retrorectal tailgut cyst: clinicopathological considerations. Am J Gastroenterol. 2000; 95(5): 1344-1347. doi: 10.1111/j.1572-0241.2000.02023.x

11. Glasgow SC, Birnbaum EH, Lowney JK, Fleshman JW, Kodner IJ, Mutch DG, et al. Retrorectal tumors: a diagnostic and therapeutic challenge. Dis Colon Rectum. 2005; 48(8): 1581-1587. doi: 10.1007/s10350-005-0048-2 